\title{
Cronograma de amostragem de plantas de alface hidropônica para ajuste de curvas de crescimento
}

\author{
Hydroponic lettuce sampling chronogram for fitting growth curves \\ Paula Machado dos Santos ${ }^{\mathrm{I}}$ Sidinei José Lopes ${ }^{\mathrm{I} *}$ Alessandro Dal'Col Lúcio ${ }^{\mathrm{I}}$ \\ Osmar de Souza Santos ${ }^{\mathrm{I}}$ Valdecir José dos Santos ${ }^{\text {II }}$ Betânia Brum ${ }^{\text {II }}$
}

\section{RESUMO}

O ajuste de curvas de crescimento de plantas de alface durante seu ciclo necessita de amostragens no tempo, o que restringe o número de efeitos de tratamentos estudados. Com o objetivo de determinar o cronograma de amostragem de plantas de alface em hidroponia para o ajuste de curvas de crescimento até a fase de maturação das sementes, foram realizados dois cultivos em casa de vegetação durante a primavera e o outono, em área pertencente ao Departamento de Fitotecnia, na UFSM, Santa Maria, RS. A partir do ajuste de um modelo de crescimento com amostragem diária, simularam-se diferentes cronogramas de amostragem para o ajuste do mesmo modelo. Para encontrar o cronograma de maior intervalo entre amostragens, ou seja, menor número de coletas, foi comparado o ajuste do modelo de amostragem diária com os ajustes dos modelos dos diferentes intervalos de amostragens simulados, dois a dois, pelo teste F. Foram realizadas simulações considerando desde a data de transplante até a produção de sementes, para variáveis de fitomassa seca da planta e de partes da planta e área foliar. Em experimentos realizados com alface hidropônica na primavera, para o ciclo completo, recomendam-se amostragens a cada 3, 8, 20 e 9 dias para fitomassa seca relativa total da planta de alface, de folhas, de raiz e área foliar, respectivamente; enquanto que, para experimentos realizados no outono, é recomendável utilizar intervalos de amostragens a cada 2, 11, 12 e 11 dias, respectivamente.

Palavras-chave: fitomassa, regressão não-linear, área foliar.

\section{ABSTRACT}

The fitting of growth curves for lettuce plants requires many samplings within o time interval, while can restrict the number of studied treatments. With the aim o determine sampling chronogram hidroponic lettuce for the fitting of growth curves until maturation of seeds. Two greenhouse trials were carried out in spring an autumn, at UFSM experimental area, Santa Maria, RS. Different sampling interval were simulated using the fitting of a daily model. The optimum sampling interval were determined by comparing daily sampling model with simulated sampling model by $F$ test. Simulations were carried between out for the following variables: total leaf, root and leaf area phytomass. Based on trials carried out during spring it is recommended sampling in intervals of three (total), eight (leaf), 20 (roots) and nine (leaf area) days and for carried out in autumn the sampling interval should be of two, 11, 12 and 11 days.

Key words: non linear regression, phytomass, foliar area.

\section{INTRODUÇÃO}

Em hidroponia, as condições de crescimento são potenciais, ou seja, existe um suprimento ótimo de água e nutrientes, e a ocorrência de ervas daninhas, insetos-praga e doenças é altamente controlada. Portanto, a taxa de crescimento é determinada principalmente pela radiação solar e temperatura do ar (VAN KEULEN \& WOLF, 1986). Esse aspecto torna-se importante principalmente quando se procura desenvolver modelos matemáticos para a simulação de crescimento.

\footnotetext{
IDepartamento de Fitotecnia, Universidade Federal de Santa Maria (UFSM), 97105-900, Santa Maria, RS, Brasil. E-mail: sjlopes@ccr.ufsm.br.*Autor para correspondência.

${ }^{\mathrm{II}}$ Curso de Agronomia, UFSM, Santa Maria, RS, Brasil.
} 
Para a utilização dos modelos matemáticos de crescimento e desenvolvimento de plantas, existe a necessidade de determinação de seus parâmetros empíricos através de experimentação, com a necessidade de várias amostragens. No caso de amostragens, em que parte da planta é destruída, há interferência na população restante. Na análise quantitativa de crescimento de comunidades vegetais, os intervalos de amostragens mais utilizados variam entre sete e 14 dias (PEREIRA \& MACHADO, 1987; LIMA, 1995) e são determinados de forma empírica. Portanto, o tamanho dos experimentos deve ser determinado em função do número de amostragens necessárias no tempo.

Experimentos conduzidos sob ambientes controlados dispõem de áreas restritas, tornando ainda mais importante a determinação de um intervalo em que são coletadas amostras de plantas, buscando uma representação eficiente de curvas para análise de crescimento e, conseqüentemente, reduzindo o efeito destrutivo das amostragens sem comprometer a precisão dos ensaios.

Existe a tendência de coletas semanais para o estudo do crescimento da cultura de alface, porém com a primeira coleta em diferentes números de dias após o transplante. SEGOVIA et al. (1997) realizaram trabalho comparando o crescimento e o desenvolvimento de três cultivares de alface durante o inverno, no interior de casa de vegetação, em Santa Maria, RS, coletando quatro plantas por parcela a cada sete dias, durante o transcorrer do ciclo vegetativo. MEDEIROS et al. (2001) também utilizaram coletas semanais para determinar índices de crescimento e desenvolvimento de alface.

Com isso, torna-se importante a determinação do intervalo em que são coletadas as amostras de plantas para melhor representar as curvas de crescimento, buscando reduzir o efeito destrutivo das amostragens, sem comprometer a precisão dos experimentos e evitando o desperdício de tempo e recursos financeiros.

O presente trabalho teve como objetivo determinar o cronograma de amostragem de plantas de alface em hidroponia para ajuste de curvas de crescimento, desde o transplante até a produção de sementes, em duas épocas de cultivo.

\section{MATERIAL E MÉTODOS}

Foram conduzidos dois experimentos sob ambiente controlado, em casa de vegetação do Departamento de Fitotecnia da Universidade Federal de Santa Maria, localizada no município de Santa Maria, RS: 5348’42”O; 2941'25”S; e 95m de altitude.

Os experimentos foram realizados nos períodos de 20/09/2004 a 12/01/2005 e 27/02/2005 a 20/ $07 / 2005$, durante as estações de cultivo de primavera e outono, respectivamente, sendo conduzidos sob o sistema NFT (Nutrient Film Technique) de cultivo em hidroponia, em bancadas de perfis hidropônicos $\left(\right.$ Hidrogood $^{\circledR}$ ) sob estufa plástica de 10 x 25m, com piso de concreto, modelo arco, coberta com policloreto de vinil plastificado com espessura de $0,0002 \mathrm{~m}$, aditivado contra raios ultravioleta. A solução nutritiva utilizada foi a proposta por CASTELLANE \& ARAÚJO (1995). A cultivar de alface utilizada foi a "Regina”, do tipo lisa, indicada para plantio durante todo o ano.

Em ambos os experimentos, as mudas foram produzidas em placas de espuma fenólica para germinação. Durante o período que compreendeu a semeadura, germinação e formação de plântulas (até três folhas mais as duas folhas cotiledonares), as espumas foram acondicionadas em um berçário de fibrocimento. A solução nutritiva utilizada para o berçário foi a proposta por CASTELLANE \& ARAÚJO (1995), com concentração igual a 50\% do total recomendado. O transplante foi realizado após a formação das mudas para perfis hidropônicos com $0,25 \mathrm{~m}$ de espaçamento entre as plantas nas bancadas, com $100 \%$ da formulação original da solução nutritiva.

O início da coleta de amostras ocorreu desde o primeiro dia após o transplante (DAT) até quando as plantas apresentavam 50\% dos aquênios maduros, quando foi realizada a colheita. Diariamente, às oito horas da manhã, coletou-se aleatoriamente três plantas, havendo uma planta em cada extremidade da amostra como bordadura. Para a quantificação da fitomassa, a planta coletada foi separada em partes: raiz, talo, folhas verdes e senescentes, e retirados discos foliares de área conhecida para a determinação da área foliar pelo método de discos foliares.

A partir do primeiro DAT, caracterizou-se a duração do crescimento da planta conforme os grausdia acumulados em ${ }^{\circ} \mathrm{C}$ dia na seguinte equação: 


$$
G D_{1}=\sum_{i=1}^{n i}\left(\bar{T}_{i}-T_{B I}\right) / G D_{p m p} \text { com: } \quad \bar{T}_{i}\left(\text { Tmáx }_{i}+\text { Tmín }_{i}\right) / 2,
$$

em que: $\overline{T_{i}}$ se refere à temperatura média diária do ar $\left({ }^{\circ} \mathrm{C}\right)$; Tmáx $\mathrm{i}_{\mathrm{i}}$ e Tmín, às temperaturas $\left({ }^{\circ} \mathrm{C}\right)$ máxima e mínima do ar; $\mathrm{GD}_{\mathrm{pmf}}$, ao índice térmico da cultura correspondente ao ponto de maturidade fisiológica $\left({ }^{\circ} \mathrm{C}\right.$ dia); $\mathrm{T}_{\mathrm{B}}$, à temperatura basal da cultura de alface $\left(10^{\circ} \mathrm{C}\right.$, conforme BRUNINI et al., 1976). As temperaturas máximas e mínimas do ar foram verificadas diariamente, às 18 horas, no interior da estufa.

Constituíram-se as bases teóricas do modelo empírico do cosseno (DOURADO NETO et al., 1998) pela validação dos valores extremos da variação temporal diária de fitomassa seca relativa total da planta $\left(\mathrm{FSTr}_{\mathrm{i}}=\right.$ raiz + talo + folhas + discos $)$, das raízes $\left.(\mathrm{FSRr})_{\mathrm{i}}\right)$, das folhas $\left(\mathrm{FSFr}_{\mathrm{i}}=\right.$ folhas verdes e senescentes) e área foliar relativa $\left(\mathrm{AFr}_{\mathrm{i}}\right)$ em função da soma térmica, caracterizada por graus-dia acumulados. Utilizaram-se valores relativos, ou seja, entre zero e um, para fins de extrapolação, sendo que cada valor de fitomassa observado no i-ésimo DAT foi dividido pelo maior valor de fitomassa observado durante todo o ciclo. Para a fitomassa seca total e de raízes, pressupôs-se que seu máximo valor foi alcançado no ponto de maturidade fisiológica, no qual a taxa de acúmulo é nula, enquanto que, para fitomassa seca de folhas e área foliar, o máximo valor ocorreu antes da maturidade fisiológica. Para o ajuste dos dados ao modelo do cosseno, inseriram-se parâmetros empíricos, estimados pelo programa computacional Table Curve 2D v.2.03 (Jandel Scientific), utilizando-se o procedimento iterativo para mínimos quadrados não-lineares de LevembergMarquardt:

$$
\begin{aligned}
& F \hat{S} T r_{i}=\frac{\cos ^{\alpha}\left\{\frac{\pi}{2}\left(1-G D_{i}\right)^{\beta}\right\}}{\delta},(\alpha, \beta, \delta \in \mathfrak{R}) \\
& F \hat{S} F r_{i}=\frac{\cos ^{\alpha}\left\{\frac{\pi}{2}\left(\frac{G D_{(X) m}-G D_{i}}{G D_{(X) m}}\right)^{\beta}\right\}}{\delta},(\alpha, \beta, \delta \in \mathfrak{R}) \\
& F \hat{S} R r_{i}=\frac{\cos ^{\alpha}\left\{\frac{\pi}{2}\left(1-G D_{i}\right)^{\beta}\right\}}{\delta},(\alpha, \beta, \delta \in \mathfrak{R}) \\
& \hat{A} F r_{i}=\frac{\cos ^{\alpha}\left\{\frac{\pi}{2}\left(\frac{G D_{(X) m}-G D_{i}}{G D_{(X) m}}\right)^{\beta}\right\}}{\delta},(\alpha, \beta, \delta \in \mathfrak{R})
\end{aligned}
$$

Definiu-se cronograma de amostragem como sendo o número de datas de coleta de plantas com intervalos constantes entre duas amostragens seguidas. Assim, um maior intervalo entre amostragens equivale a um menor número de amostragens durante o ciclo da planta.

A partir do ajuste do modelo cosseno com amostragem diária, simularam-se diferentes cronogramas de amostragem, para o ajuste do mesmo modelo. Objetivando o cronograma de maior intervalo entre amostragens, foi comparado o ajuste do modelo de amostragem diária com os ajustes dos modelos dos diferentes intervalos constantes entre amostragens simulados, desde intervalos de um dia até 25 dias entre cada data de amostragem. Por exemplo, simulou-se o cronograma de amostragem com um intervalo de dois dias entre uma data e outra a partir do primeiro DAT até a colheita, ou seja, num ciclo de 100 dias, realizar-seiam 50 amostragens. O mesmo processo foi simulado para cronogramas com intervalos entre datas de amostragens de três a 25 dias.

Para encontrar o cronograma ideal de amostragem, ou seja, o cronograma de maior intervalo entre datas de amostragens, foram comparados o cronograma de amostragem diária com todos os cronogramas simulados, dois a dois, pelo teste $\mathrm{F}$ em nível de 5\% de probabilidade de erro, com a razão das estimativas de máxima verossimilhança da variância residual (Equação 5), ou seja, os quadrados médios do erro (QME) da análise de regressão não-linear ponderados pelos respectivos graus de liberdade (RATKOWSKY, 1983).

$$
Q M E=\left[\sum_{i=1}^{n}\left(Y_{i}-\hat{Y}_{i}\right)^{2} /(\eta-3)\right]
$$

em que, $Y_{i}$ se refere aos valores observados no i-ésimo dia de amostragem; $\hat{Y}_{i}$ aos valores estimados; e $\eta$ ao número de amostragens.

O modelo de maior intervalo entre datas de amostragens que não diferisse do modelo de amostragem diária foi considerado o cronograma ideal de amostragem.

Para cada cronograma simulado, consideraram-se sete repetições: coletas iniciadas a partir do primeiro, segundo, terceiro, quarto, quinto, sexto e sétimo DAT, para cada época e variável. Adotaram-se como critérios de escolha do cronograma 
ideal de amostragem o cronograma de amostragem modal entre as sete repetições. Caso não existisse moda dos números de intervalos de amostragens entre as sete repetições, optou-se pelo menor intervalo de amostragem que não diferisse do cronograma diário.

\section{RESULTADOS E DISCUSSÃO}

Estão apresentados nas figuras 1 a 4 os modelos de crescimento da planta de alface, em função da soma térmica, obtidos através de coletas de amostras diárias e com cronogramas de amostragem que diferiram do cronograma simulado, pelo teste F. Considerandose que o cronograma simulado superestima ou subestima o crescimento das plantas, quando comparados com o modelo de crescimento do cronograma diário de amostragem.

Na estimativa de curvas de crescimento, LOPES et al. (2004) sugerem existir diferença na necessidade de intervalos de amostragem entre os períodos vegetativos e reprodutivos do ciclo. Esta observação pode ser considerada quando se verifica que, durante o transcorrer de todo o ciclo da alface, existe a translocação de fotoassimilados das folhas para os órgãos reprodutivos, diminuindo a taxa de crescimento da planta.

Sabe-se que o crescimento das plantas, quantificado em acúmulo de fitomassa seca pelo tempo,

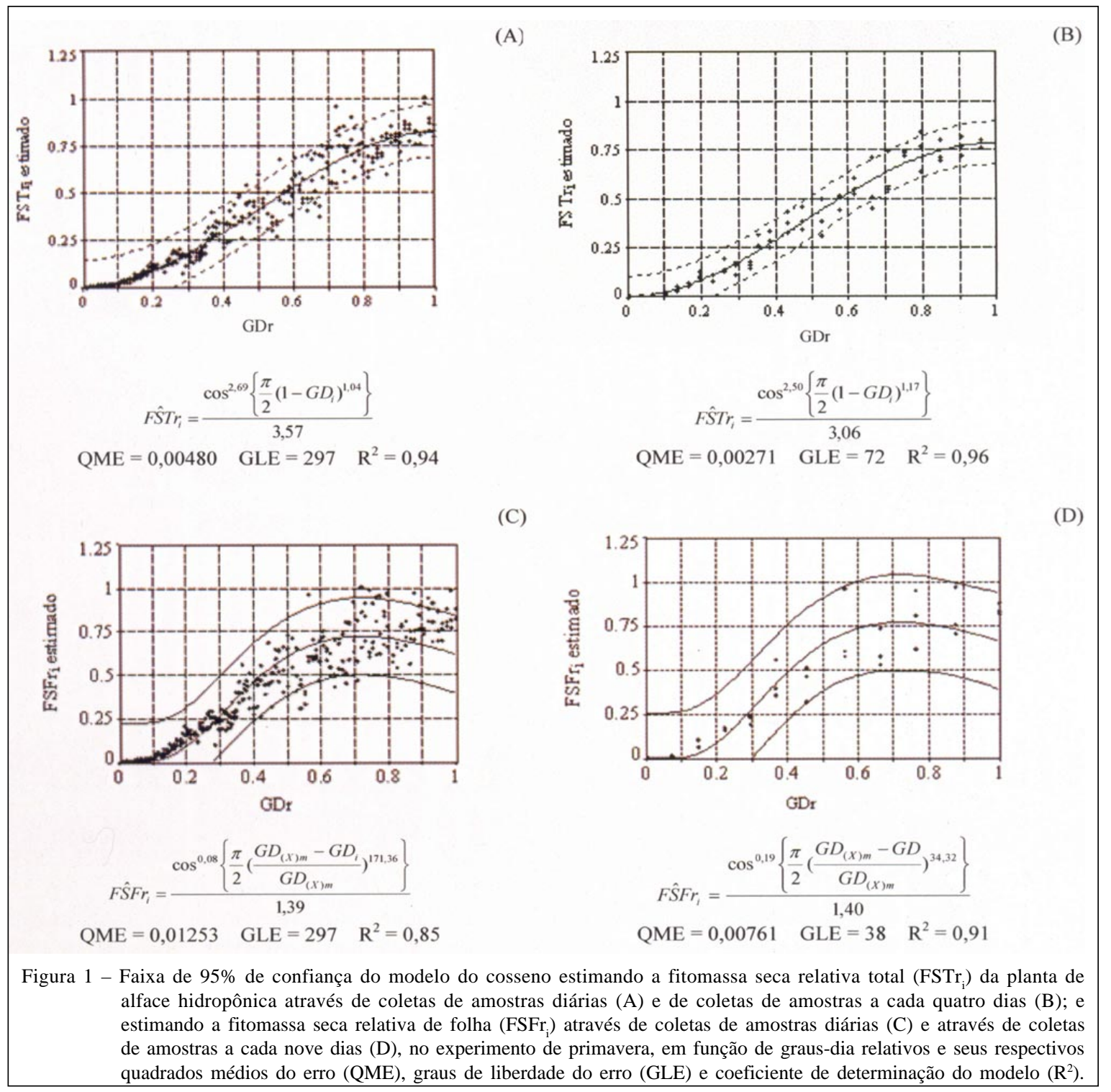

Ciência Rural, v.37, n.6, nov-dez, 2007. 


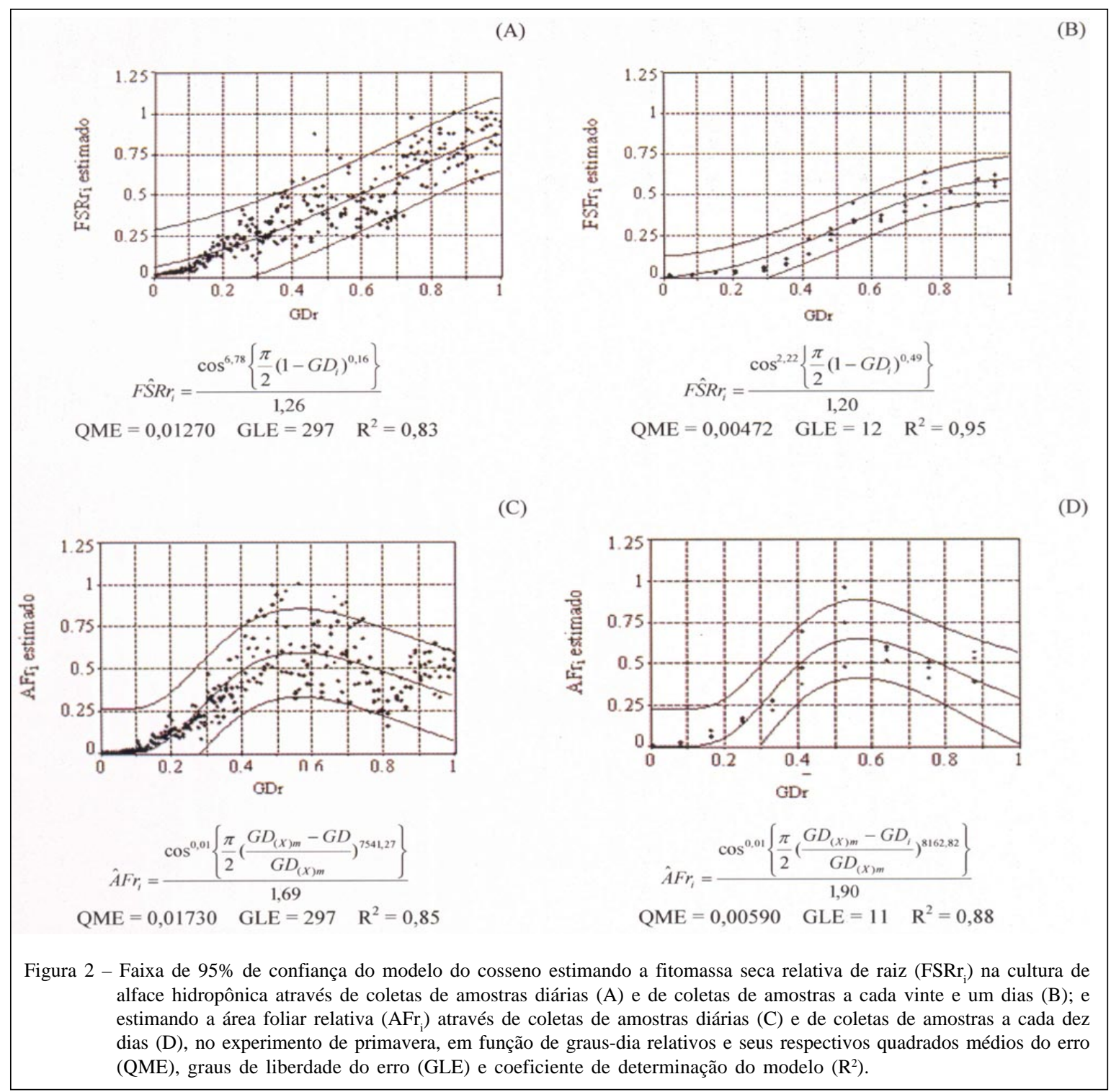

segue aproximadamente uma curva sigmóide, ou seja, no início do crescimento a fitomassa seca de plantas individuais aumenta em proporção constante por dia, então conduzindo para um crescimento exponencial.

Depois de a cultura fechar a superfície, mais folhas crescem sem conduzir a uma proporcional interceptação de luz. Conseqüentemente, a taxa de crescimento permanece constante e a fitomassa total da planta aumenta linearmente até um ponto de inflexão (máxima taxa de acúmulo de fitomassa seca). A partir desse ponto, a taxa de crescimento começa a diminuir até a curva se aproximar do ponto de maturidade fisiológica ou assíntota da curva (Figuras 1 a 4).

Verifica-se que quanto maior for o ciclo da planta (outono), maior será o número de observações, havendo um aumento no número de graus de liberdade (GLE=384), que permite maior similaridade entre os quadrados médios dos erros dos modelos (Figura 3 e 4). Assim há uma diferença na exigência de intervalos de amostragens segundo as diferentes variáveis e a duração do ciclo da planta.

A variável $\mathrm{FSTr}_{\mathrm{i}}$ necessita de intervalos menores entre amostragens, a cada três dias, se o comparada às demais variáveis, tanto para o experimento de primavera como para o de outono. Possivelmente, este fato relaciona-se com a maior variação da translocação dos fotoassimilados para as diferentes partes da planta durante o ciclo da cultura de alface, que ocorre principalmente na transição entre o período vegetativo e o reprodutivo. No entanto, ao 


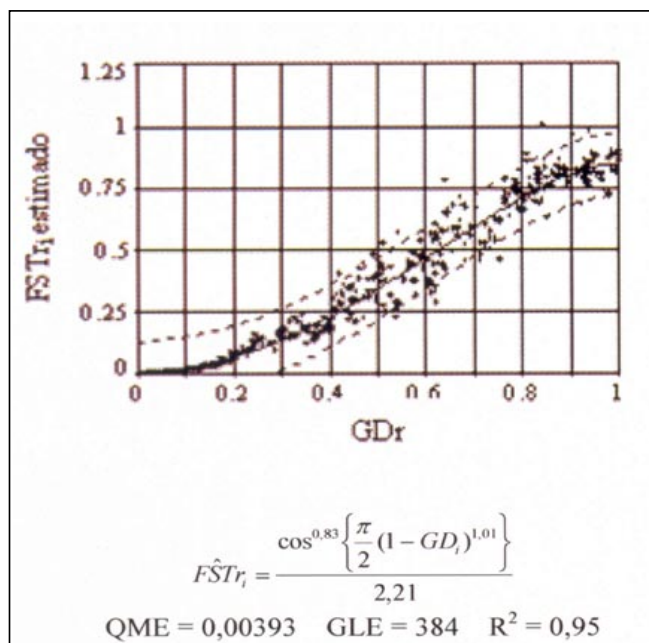

(A)

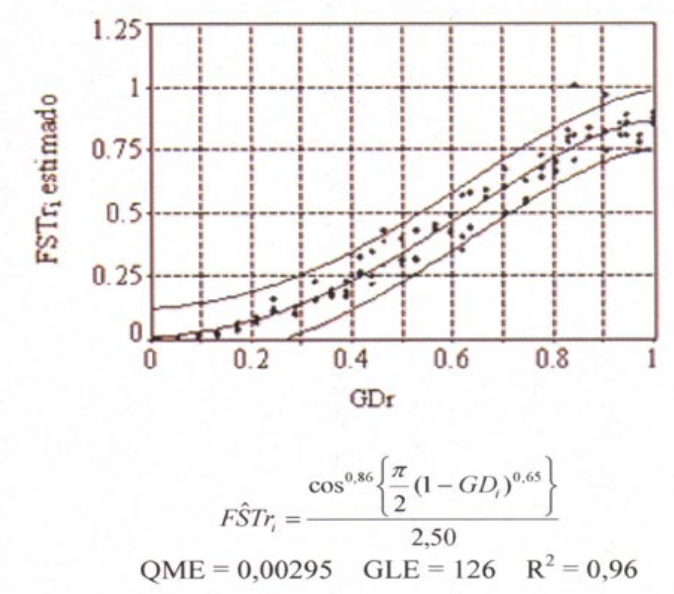

(C)
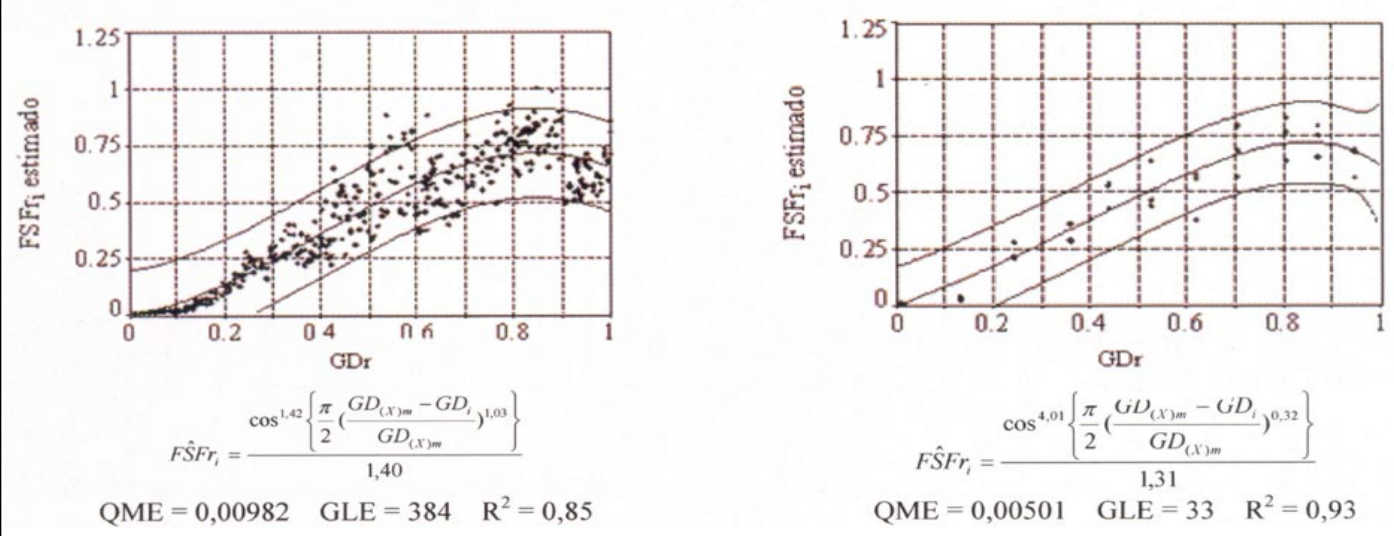

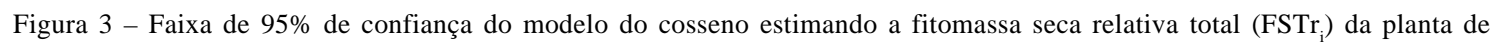
alface hidropônica através de coletas de amostras diárias (A) e de coletas de amostras a cada quatro dias (B); e estimando a fitomassa seca relativa de folha $\left(\mathrm{FSFr}_{\mathrm{i}}\right.$ ) através de coletas de amostras diárias (C) e de coletas de amostras a cada doze dias (D), no experimento de outono, em função de graus-dia relativos e seus respectivos quadrados médios do erro (QME), graus de liberdade do erro (GLE) e coeficiente de determinação do modelo $\left(\mathrm{R}^{2}\right)$.

se considerarem as variáveis $\mathrm{FSFr}_{\mathrm{i}}, \mathrm{FSRr}_{\mathrm{i}}$ e $\mathrm{AFr}_{\mathrm{i}}$, isoladamente, a exigência de intervalos é maior, ou seja, menor número de amostragens de plantas. A FSFr ${ }_{\mathrm{i}}$ pode ser avaliada por intervalos de oito e onze dias para os experimentos na primavera e no outono, respectivamente.

A área foliar relativa apresenta resultados de intervalos entre amostragens de nove e 11 dias para os experimentos realizados na primavera e no outono, respectivamente, próximos aos encontrados para a variável fitomassa seca relativa de folhas, devido à correlação linear entre ambas.

Na estimação dos intervalos de amostragens para as sete repetições de cada cronograma simulado, segundo diferentes dias para o início das coletas de amostras de planta (Figura 5), verifica-se que os valores encontrados, no experimento de outono, apresentaram maior variação entre os dias de início de coleta. Este resultado pode ser atribuído à perda de área foliar ocorrida pelo ataque do fungo Esclerotinia sclerotiorum. Os danos foram observados a partir dos 82 DAT, correspondente ao início da elongação do talo, no início do período reprodutivo no outono. Nas folhas mais velhas, encontraram-se manchas de aparência amarelada formando anéis concêntricos. As estruturas de esclerócios foram encontradas tanto nas folhas, como nos talos e raízes, afetando a maioria das plantas do experimento pela contaminação do sistema hidropônico. Através do tratamento da doença, conseguiu-se estabilizar a fitomassa verde das folhas, 

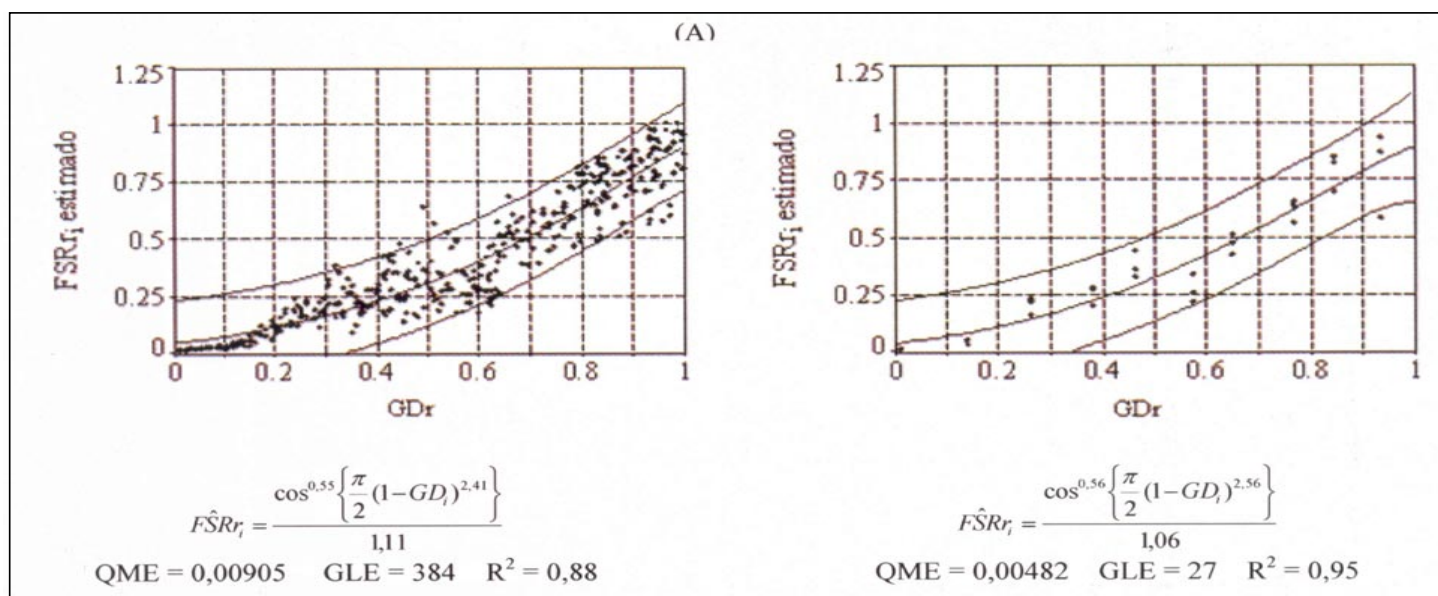

(C)
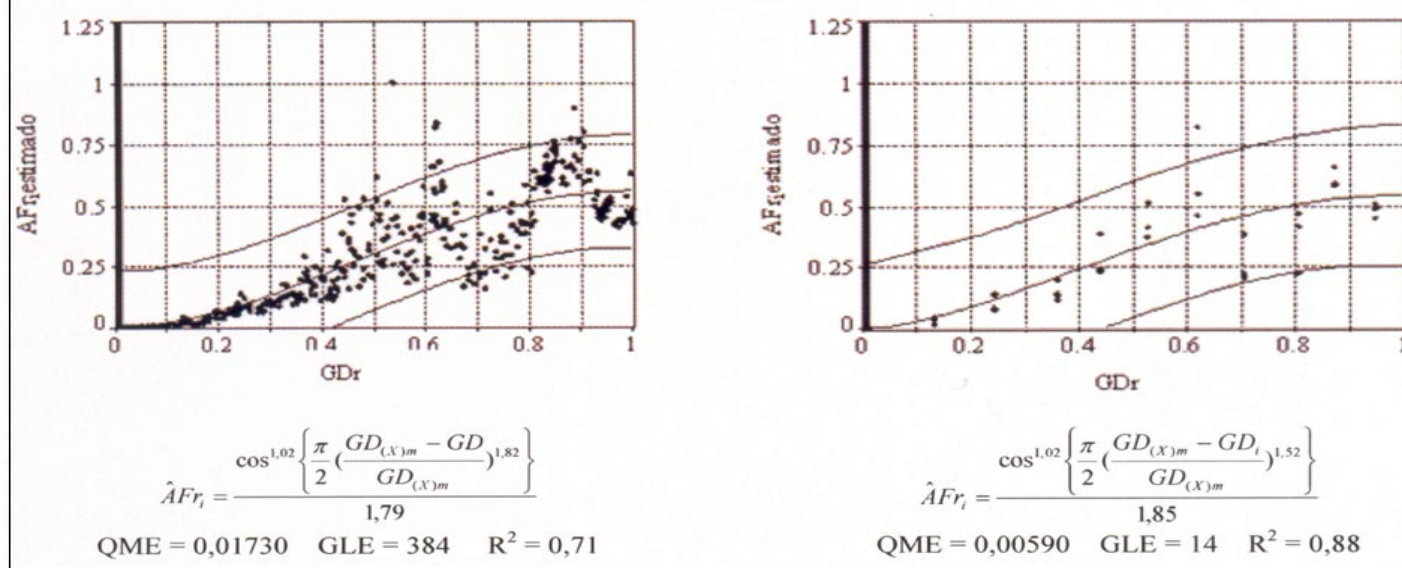

Figura 4 - Faixa de 95\% de confiança do modelo do cosseno estimando a fitomassa seca relativa de raiz (FSRr ( $_{\mathrm{i}}$ na cultura de alface hidropônica através de coletas de amostras diárias (A) e de coletas de amostras a cada treze dias (B); e estimando a área foliar relativa ( $\mathrm{AFr}_{\mathrm{i}}$ ) através de coletas de amostras diárias $(\mathrm{C})$ e de coletas de amostras a cada doze dias (D), no experimento de outono, em função de graus-dia relativos e seus respectivos quadrados médios do erro (QME), graus de liberdade do erro (GLE) e coeficiente de determinação do modelo ( $\mathrm{R}^{2}$ ).

e o controle não impediu que houvesse o surgimento de novas folhas, com brotações laterais, e o posterior surgimento das inflorescências.

A área foliar relativa no experimento de primavera, entre as sete repetições, não apresentou nenhum resultado igual, ou seja, não foi encontrada a moda do conjunto de dados. Então, foi adotado o menor intervalo entre amostragens como referência para o intervalo de dias entre coletas, a cada nove dias.

A recomendação do cronograma de amostragem é específica para cada variável; no entanto, o cronograma de amostragem deve ser realizado segundo o interesse do pesquisador. Sugere-se o cronograma de coleta de plantas da fitomassa seca relativa total da planta de alface que apresentou maior exigência em datas de amostragem em ambos os períodos do que as demais variáveis de fitomassa, pois, no momento da coleta, é normalmente realizada a quantificação das demais partes da planta que também se deseja estimar.

\section{CONCLUSÕES}

O cronograma de amostragens para ajuste de curvas de crescimento de plantas de alface em cultivo hidropônico é, para o experimento de primavera, de: 3, 8, 20 e 9 dias; e, para o experimento de outono, de: $3,12,11$ e 12 dias, para as variáveis fitomassa seca relativa total da planta, de folha, de raiz e área foliar relativa, respectivamente.

Ciência Rural, v.37, n.6, nov-dez, 2007. 


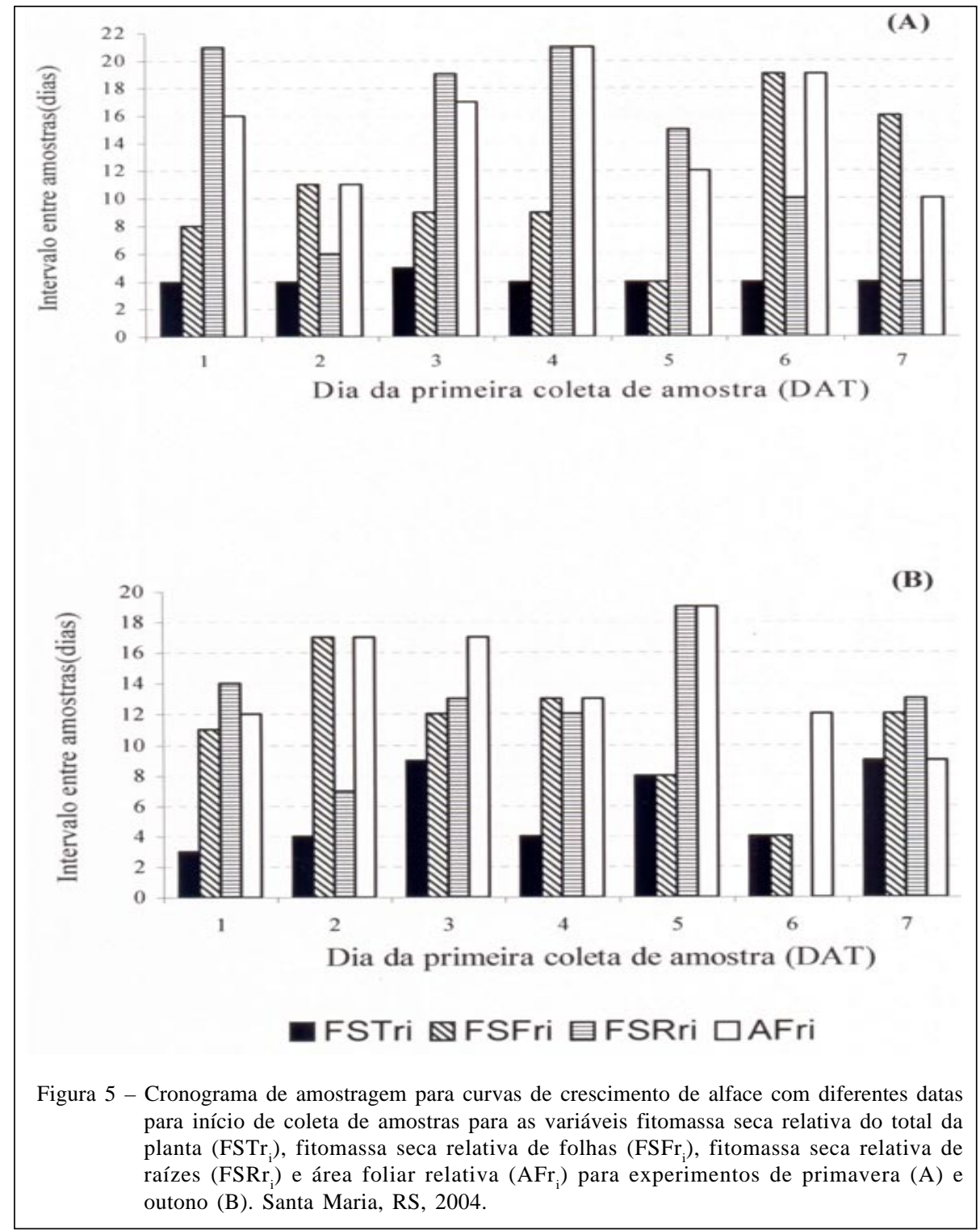

\section{REFERÊNCIAS}

BRUNINI, O. et al. Temperatura-base para alface cultivar "white boston", em um sistema de unidades térmicas. Bragantia, v.35, p.213-219, 1976.

CASTELLANE, P.D.; ARAÚJO, J.A.C. de. Cultivo sem solo: hidroponia. 4.ed. Jaboticabal: FUNEP, 1995. 43p.

DOURADO NETO, D. et al. Principles of crop modeling and simulation. I. Uses of mathematical models in agriculture science. Scientia Agricola, v.55, p.46-50, 1998.

LIMA, M.G. Calibração e validação do modelo CeresMaize em condições tropicais do Brasil. 1995. $119 f$. Tese (Doutorado em Fitotecnia) - Escola Superior de Agricultura “Luís de Queiroz”, Universidade de São Paulo, Piracicaba.

LOPES, S.J. et al. Models to estimate phytomass accumulation of hydroponic lettuce. Scientia Agricola, v.61, n.4, p.392400, 2004.
MEDEIROS, L.A.M. et al. Crescimento e desenvolvimento da alface (Lactuca sativa L.) conduzida em estufa plástica com fertirrigação em substratos. Ciência Rural, v.31, n.2, p.199204, 2001.

PEREIRA, A.R; MACHADO, E.C. Análise quantitativa do crescimento e desenvolvimento de comunidade vegetal. Campinas: Instituto Agronômico, 1987. 33p. (Boletim Técnico, 114).

RATKOWSKY, D.A. Nonlinear regression modeling - A unified practical approach. New York and Basel: Marcel Dekker, 1983. 276p.

SEGOVIA, J.F.O. et al. Comparação do crescimento e desenvolvimento da alface (Lactuca sativa L.) no interior e no exterior de uma estufa de polietileno em Santa Maria, RS. Ciência Rural, v.27, n.1, p.37-41, 1997.

VAN KEULEN, H.; WOLF, J. Modelling of agricultural production, weather, soil and crops. Wageningen: The Netherlands, 1986. 613p. 